Supporting information

\title{
Structural Transformation of Pt-Ni Nanowires as Oxygen Reduction Electrocatalysts to Branched Nanostructures during Potential Cycles
}

Masaru Kato, ${ }^{* 1,2}$ Yoshimi Iguchi, ${ }^{2}$ Tianchi Li, ${ }^{2}$ Yuta Kato, ${ }^{2}$ Yu Zhuang, ${ }^{2}$ Kotaro Higashi, ${ }^{3}$ Tomoya Uruga, ${ }^{3,4}$ Takahiro Saida, ${ }^{5}$ Keiko Miyabayashi, ${ }^{6}$ Ichizo Yagi*,1,2

${ }^{1}$ Faculty of Environmental Earth Science, Hokkaido University, N10W5, Kita-ku, Sapporo 060-0810, Japan

${ }^{2}$ Graduate School of Environmental Science, Hokkaido University, N10W5, Kita-ku, Sapporo 060-0810, Japan

${ }^{3}$ Innovation Research Center for Fuel Cells, The University of Electro-Communications, Chofugaoka, Chofu, Tokyo 182-8585, Japan

${ }^{4} J a p a n$ Synchrotron Radiation Research Institute, SPring-8, Sayo, Hyogo 679-5198, Japan

${ }^{5}$ Department of Applied Chemistry, Meijo University, Nagoya 468-8502, Japan

${ }^{6}$ Graduate School of Integrated Science and Technology, Shizuoka University, 3-5-1, Naka-ku, Hamamatsu, Shizuoka, 432-8561, Japan

E-mail: masaru.kato@ees.hokudai.ac.jp (to MK); iyagi@ees.hokudai.ac.jp (to IY) 


\section{Experimental section}

\section{Materials.}

Ethanol, cyclohexane, 2-propanol, perchloric acid, oleylamine, $\mathrm{D}(+)$-glucose and 5\% Nafion DE520 were purchased from Wako Pure Chemical Industries, Ltd. [Pt(acac $\left.)_{2}\right]$ and $\mathrm{Pt} / \mathrm{C}$ (TEC10V30E) was purchased from Tanaka Kikinzoku Kogyo. Hexadecyltrimethylammonium chloride (CTAC), $\left[\mathrm{Mo}(\mathrm{CO})_{6}\right]$ and $\left[\mathrm{Ni}(\mathrm{acac})_{2}\right]$ were commercially available from TCI, Kanto Chemical and Sigma-Aldrich, respectively. Pure oxygen gas (99.995\%, Air Liquide Japan), pure argon gas (99.9995\%, Hokkaido Air Water) and CO gas (99.9\%, GL Science) were used for electrochemical measurements.

\section{Preparation of Pt-Ni nanowires.}

$\mathrm{Pt}-\mathrm{Ni}$ nanowires were prepared in a modified synthetic procedure based on reported synthetic procedures. ${ }^{1-2}$ In $5 \mathrm{~mL}$ of oleylamine $(15 \mathrm{mmol})$ in a two-necked round bottom flask $(100 \mathrm{~mL}), 10 \mathrm{mg}$ of $\left[\mathrm{Pt}(\mathrm{acac})_{2}\right](0.025 \mathrm{mmol}), 6.4 \mathrm{mg}$ of $\left[\mathrm{Ni}(\mathrm{acac})_{2}\right](0.025 \mathrm{mmol})$, $10 \mathrm{mg}$ of CTAC $(0.031 \mathrm{mmol}), 20 \mathrm{mg}$ of $\left[\mathrm{Mo}(\mathrm{CO})_{6}\right](0.075 \mathrm{mmol})$, and $60 \mathrm{mg}$ of Dglucose $(0.33 \mathrm{mmol})$ were added. The dispersion was kept at ca. $298 \mathrm{~K}$ in water under ultrasonication for $30 \mathrm{~min}$ and then stirred at $<343 \mathrm{~K}$ under Ar. After ca. $5 \mathrm{~min}$, the solution mixture became transparent and green. The reaction mixture was transferred to a pre-heated oil bath at $433 \mathrm{~K}$ and then kept with stirring at $433 \mathrm{~K}$ under Ar for $2 \mathrm{~h}$. The reaction mixture was naturally cooled down in the air to room temperature. A solution mixture (ca. $15 \mathrm{~mL}$ ) of ethanol and cyclohexane $(8: 2, v / v)$ was added to the reaction mixture and then the mixture was centrifuged at 9,500 rpm at $298 \mathrm{~K}$ for 5 min using a Micro Refrigerated Centrifuge 3700 equipped with an angle rotor AF-5004CA (Kubota Co.). The supernatant was removed, and the isolated product was rinsed with ca. $15 \mathrm{~mL}$ of ethanol-cyclohexane solvent mixture $(8: 2, v / v)$ for at least five times under centrifugation at 9,500 rpm at $298 \mathrm{~K}$ for 5 min to obtain Pt-Ni nanowires $\left(\mathrm{NW}_{\mathrm{Ar}}\right)$, which also contain Pt-Ni@Ni core-shell nanoparticles. The nanowires were stored in ethanol at room temperature until use. Yield: ca. $5 \mathrm{mg}$.

$\mathrm{Pt}-\mathrm{Ni}$ nanowires were also prepared under the air. The heat treatment under the air gave the exclusive nanowires $\left(\mathrm{NW}_{\text {air }}\right.$ in the main text).

\section{Preparation of Pt-Ni nanowires supported on carbon supports.}

Vulcan XC-72 (ca. $2.3 \mathrm{mg}$ ) and Pt-Ni nanowires (ca. $1 \mathrm{mg}$ ) were dispersed in $15 \mathrm{~mL}$ of an ethanol-cyclohexane mixture $(1: 1, v / v)$ and then kept in an ice-water mixture under ultrasonication for at least four hours. The composite was centrifuged down at $9500 \mathrm{rpm}$ 
at $298 \mathrm{~K}$ for $5 \mathrm{~min}$ and then rinsed with ca. $15 \mathrm{~mL}$ of ethanol-cyclohexane solvent mixture $(8: 2, v / v)$ for at least five times under centrifugation at $9,500 \mathrm{rpm}$ at $298 \mathrm{~K}$ for $5 \mathrm{~min}$. The composite was stored in a minimum amount of ethanol (ca. $2 \mathrm{~mL}$ ) at room temperature until use.

\section{Inductively coupled plasma mass spectrometry (ICP-MS).}

ICP-MS was performed using an ICP-MS spectrometer 8800 ICP-QQQ (Agilent Technologies). For sample preparation, a catalyst ink or the catalyst film, which was scraped off from the GC electrode after use, was dispersed in aqua regia solution and then the dispersion was stirred at $308 \mathrm{~K}$ for at least $24 \mathrm{~h}$. The dispersion was filtered through a membrane filter (13HP045AN, ADVANTEC), and then the filtrate was diluted with Milli-Q water.

\section{Scanning transmission electron microscopy (STEM) and}

STEM images were taken at an acceleration voltage of $200 \mathrm{kV}$ using HD-2000 (Hitachi Scientific Instrument). High-angle annular dark field (HAADF)-STEM images and energy dispersive X-ray spectroscopy (EDS) elemental maps were taken using a JEOL JEM-ARM200F instrument at $200 \mathrm{kV}$.

\section{Electrochemical measurements.}

All electrochemical measurements were performed using a conventional threeelectrode setup. A potentiostat (HZ-7000, Hokuto Denko) was used to perform cyclic voltammetry (CV) and linear sweep voltammetry (LSV). A rotating disk electrode (RDE) was used as the working electrode. $\mathrm{An} \mathrm{Ag} \mid \mathrm{AgCl}$ (sat. $\mathrm{KCl}$ ) electrode with a double junction holder (International chemistry Co., Ltd) and platinum foil were used as the reference electrode and the counter electrode, respectively. Catalyst-modified glassy carbon (GC) was used as the working electrode.

A GC screw (5 mm $\varphi$, M4, Tokai Carbon Co., Ltd.) or a GC disk (5 mm $\varphi$, Tokai Carbon Co., Ltd.) was polished with alumina slurry $(0.3 \mu \mathrm{m}$, Baikalox $)$, followed by alumina slurry $(0.05 \mu \mathrm{m}$, Baikalox $)$, and then sonicated in acetone and Milli-Q water for at least $5 \mathrm{~min}$ each before drop-casting a catalytic ink. To prepare the catalyst ink, $14 \mathrm{mg}$ of the catalyst was dispersed in a mixture of $6 \mathrm{~mL}$ of 2-propanol, $19 \mathrm{~mL}$ of Milli-Q water, and $100 \mu \mathrm{L}$ of $5 \%$ Nafion DE520 in a $50 \mathrm{~mL}$ glass vial in an ice-water mixture under ultrasonication for at least $2 \mathrm{~h}$. The catalyst ink $(20 \mu \mathrm{L})$ was drop-cast onto the glassy carbon disk that was rotating at 500-700 rpm using an AFMSRX Analytical Rotator and a MSRX Speed Controller (PINE Research Instrumentation) and kept at room 
temperature under rotating for ca. $1 \mathrm{~h}$ until the ink was dried. For in situ XAS measurements, the catalyst-modified GC screws were heated at $418 \mathrm{~K}$ for $5 \mathrm{~min}$ to increase the adhesion between the GC and the catalyst film.

CVs and LSVs were recorded in an aqueous solution containing $0.1 \mathrm{M} \mathrm{HClO}_{4}$. The electrolyte solution was purged with argon or oxygen for at least $30 \mathrm{~min}$ before electrochemical measurements. For electrochemical cleaning, 100 potential cycles at 200 $\mathrm{mV} \mathrm{s}^{-1}$ in the potential range between 0.05 and $1.20 \mathrm{~V}$ vs. RHE were performed in a 0.1 $\mathrm{M} \mathrm{HClO}_{4}$ aqueous solution under Ar before collecting CVs and LSVs shown in the main text. All LSVs under oxygen are corrected by the subtraction of the current densities of the corresponding working electrode recorded under Ar. All potentials are shown against the RHE.

For $\mathrm{CO}$ stripping measurements, a $0.1 \mathrm{M} \mathrm{HClO}_{4}$ aqueous electrolyte solution was purged with $\mathrm{CO}$ for $10 \mathrm{~min}$ and then with Ar for $60 \mathrm{~min}$. A bias potential of $0.05 \mathrm{~V}$ vs. RHE was applied to a sample electrode during purging with $\mathrm{CO}$ and $\mathrm{Ar}$ until the measurements began. Cyclic voltammograms were recorded in the potential range from 0.05 to $1.45 \mathrm{~V}$ vs. RHE for two cycles at $50 \mathrm{mV} \mathrm{s}^{-1}$ under Ar. Electrochemically active surface areas based on the desorption of $\mathrm{H}_{\text {upd }}$ observed in the second cycle and the electrochemical oxidation of $\mathrm{CO}$ observed in the first cycle were determined from the difference between the first and second cycles.

The mass activity (MA) of the catalysts was determined at $+0.9 \mathrm{~V}$ vs. RHE based on

the kinetically controlled current density $\left(j_{k}\right)$ obtained in the Koutechy-Levich plot for the ORR and the amount of Pt in the catalyst used on the GC electrode. The amount of Pt was determined by ICP-MS. The specific activity (SA) was determined at $+0.9 \mathrm{~V}$ vs. RHE based on the $j_{k}$ and ECSA $\mathrm{CO}_{\text {. }}$

\section{XAS measurements.}

Pt $L_{3}$-edge XAS measurements of the as-prepared $\mathrm{Pt}-\mathrm{Ni} \mathrm{NW}_{\mathrm{Ar}} / \mathrm{C}$ in the transmission method were performed at BL5S1 and BL11S2 stations in AichiSR. Boron nitride (BN) was used to make a pellet containing the sample. Pt $L_{3}$-edge XAS data were collected using a 21 Ge-element detector in a fluorescent method at BL36XU station in SPring-8. ${ }^{3}$ For in situ measurements, a RDE with a catalyst-modified GC was used as the working electrode in $0.1 \mathrm{M} \mathrm{HClO}_{4}$ under nitrogen. A platinum foil and a reversible hydrogen (International chemistry Co., Ltd) electrode were used as the counter and reference electrodes, respectively. Electrochemical data were collected using AutoLab Potential 
and Galvanostat system (Metrohm). Before in situ XAS measurements, $0.1 \mathrm{M} \mathrm{HClO}_{4}$ aqueous electrolyte solution in a polyether ether ketone (PEEK) cell was purged with nitrogen for at least $30 \mathrm{~min}$, and then 50 potential cycles at $200 \mathrm{mV} \mathrm{s}^{-1}$ were performed in the potential range from 0.05 to $1.0 \mathrm{~V}$ vs. RHE under nitrogen for electrochemical cleaning. XANES spectra of the catalysts were obtained at $0.4,0.7,0.9,1.0$ and $1.1 \mathrm{~V}$ vs. RHE. XANES spectra were normalized using Athena software. ${ }^{4}$

EXAFS oscillation data, $\chi(k)$, were extracted from the XAS data after the background subtraction. The $k^{3}$-weighted EXAFS oscillation data, $k^{3} \chi(k)$, in the $k$ range from 3 to 12 $\AA^{-1}$ were Fourier-transformed into $R$-space, followed by the inverse Fourier transform into $k$-space for curve-fitting analysis using software package REX2000 (Rigaku Co.). ${ }^{5-7}$ 

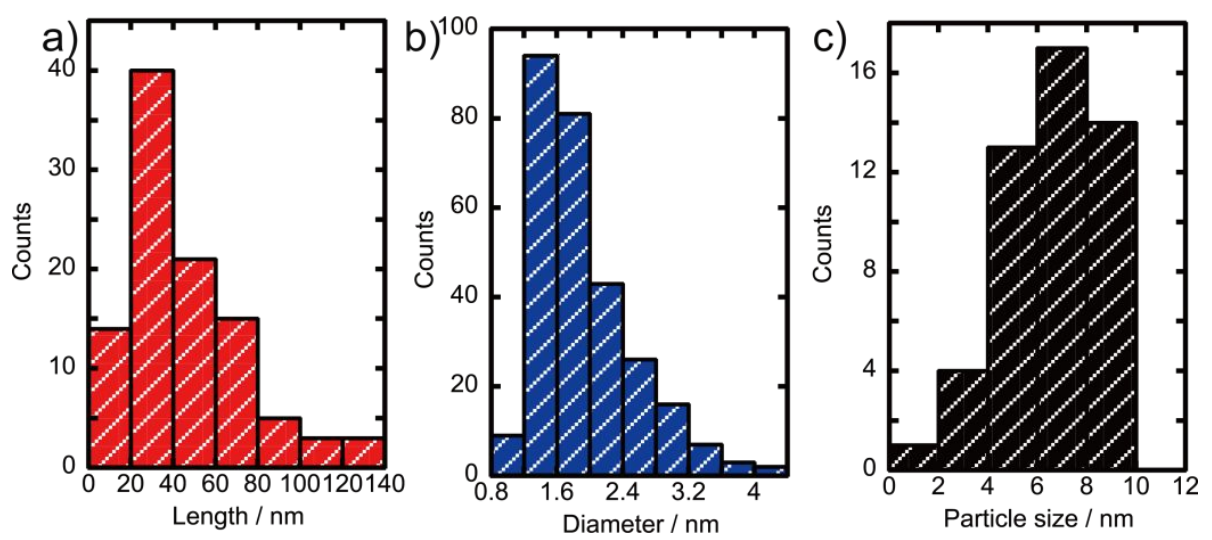

Figure S1. (a) Length and (b) diameter distributions of Pt-Ni NWs and (c) diameter distributions of NPs found in $\mathrm{NW}_{\mathrm{Ar}} / \mathrm{C}$. 

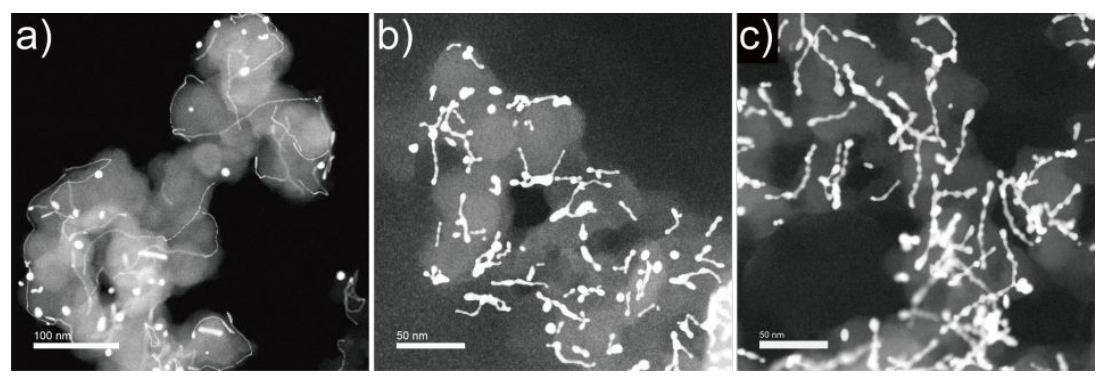

Figure S2. Representative HAADF-STEM images of (a) the as-prepared $\mathrm{NW}_{\mathrm{Ar}} / \mathrm{C}$, (b) $\mathrm{NW}_{\mathrm{Ar}} / \mathrm{C} \_25 \mathrm{k}$, and (c) $\mathrm{NW}_{\mathrm{Ar}} / \mathrm{C} \_50 \mathrm{k}$. HAADF-STEM images including these images allowed us to determine ratios of the number of NWs (and branched structures) and NPs to be 101:101 (1:1) for the as-prepared $\mathrm{NW}_{\mathrm{Ar}} / \mathrm{C}, 265: 87$ (ca. 3:1) for $\mathrm{NW}_{\mathrm{Ar}} / \mathrm{C} \_25 \mathrm{k}$, and 255:55 (ca. 5:1) for $\mathrm{NW}_{\mathrm{Ar}} / \mathrm{C} \_50 \mathrm{k}$. 

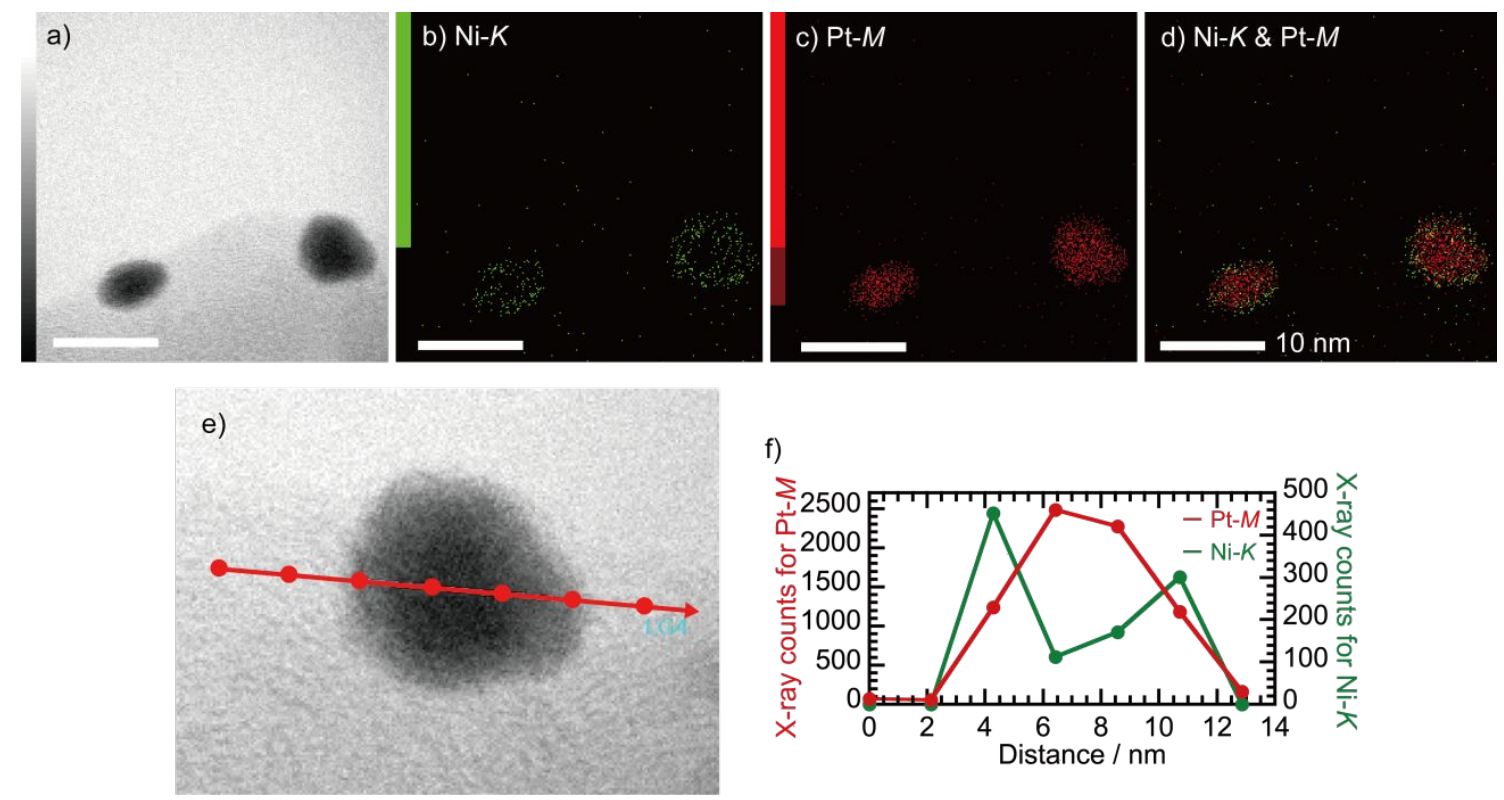

Figure S3. (a) STEM image and EDS maps of carbon-supported Pt-Ni@Ni core-shell $\mathrm{NPs}$, which co-present with $\mathrm{NW}_{\mathrm{Ar}}$, for (b) the Ni- $K$ signals in green, (c) the Pt- $M$ signals in red and (d) the overlay of Pt- $M$ and Ni- $K$ signals. (e,f) EDS line profile analysis of NPs at each point (seven points in total) for the Pt- $M$ and $\mathrm{Ni}-K$ signals. 


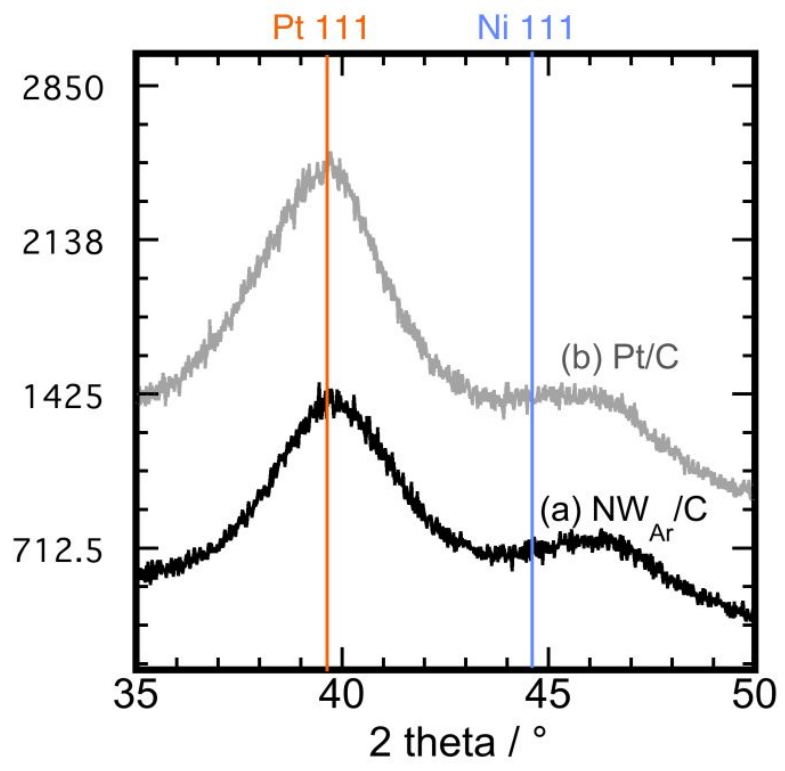

Figure S4. Power X-ray diffraction patterns of (a) the as-prepared $\mathrm{Pt}-\mathrm{Ni} \mathrm{NW}_{\mathrm{Ar}} / \mathrm{C}$ and (b) $\mathrm{Pt} / \mathrm{C}$. The orange and blue lines show the 111 diffraction position for the bulk Pt and $\mathrm{Ni}$, respectively. 


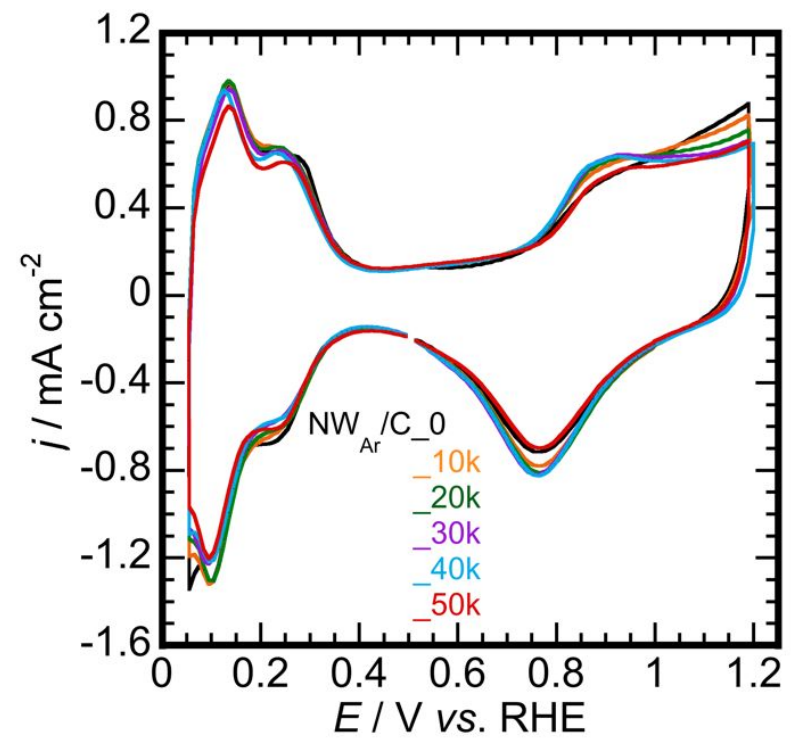

Figure S5. CVs of $\mathrm{NW}_{\mathrm{Ar}} / \mathrm{C}$ recorded at $200 \mathrm{mV} \mathrm{s}^{-1}$ in a $0.1 \mathrm{M} \mathrm{HClO}_{4}$ aqueous solution under Ar before and after potential cycles up to $50 \mathrm{k}$. CVs after $0 \mathrm{k}$ (before potential cycles), $10 \mathrm{k}, 20 \mathrm{k}, 30 \mathrm{k}, 40 \mathrm{k}$ and $50 \mathrm{k}$ potential cycles are shown in black, orange, green, purple, blue and red, respectively. 


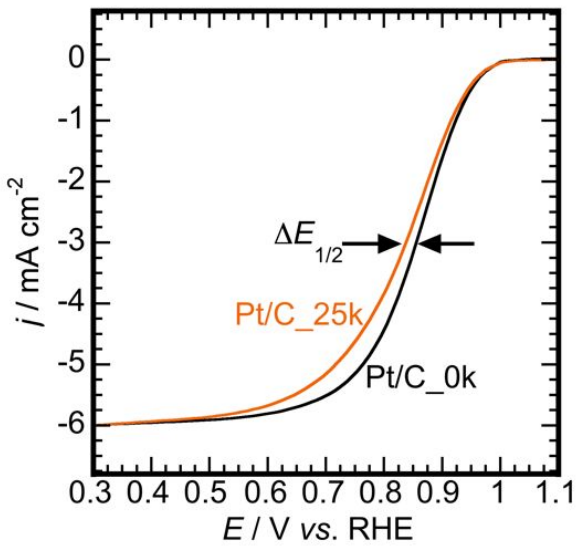

Figure S6. LSVs of $\mathrm{Pt} / \mathrm{C}$ before (the trace in black) and after $25 \mathrm{k}$ potential cycles (the trace in orange). LSVs were recorded at $1600 \mathrm{rpm}$ and $10 \mathrm{mV} \mathrm{s}^{-1}$ in a $0.1 \mathrm{M} \mathrm{HClO}_{4}$ aqueous solution under oxygen. 
a)

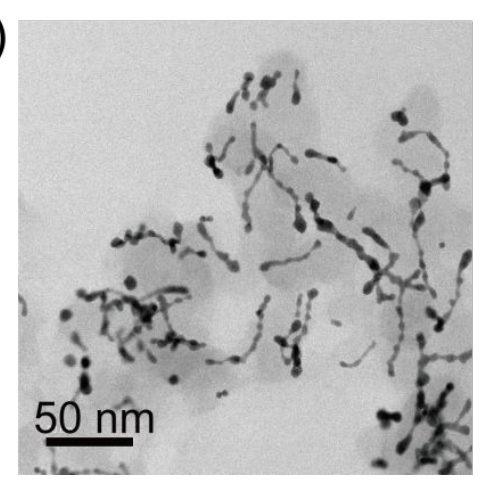

b)

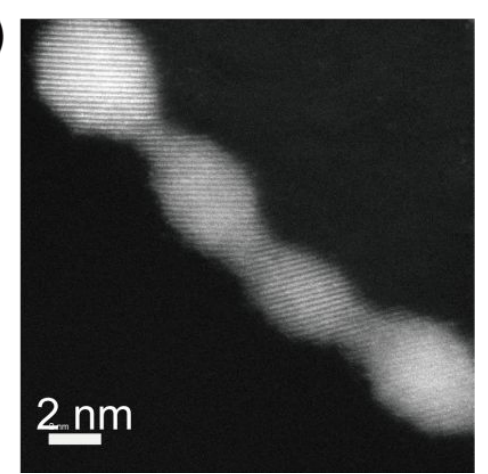

Figure S7. (a) STEM and (b) HAADF-STEM images of Pt-Ni NW $\mathrm{Ar}_{\mathrm{r}} / \mathrm{C}$ 50k. 

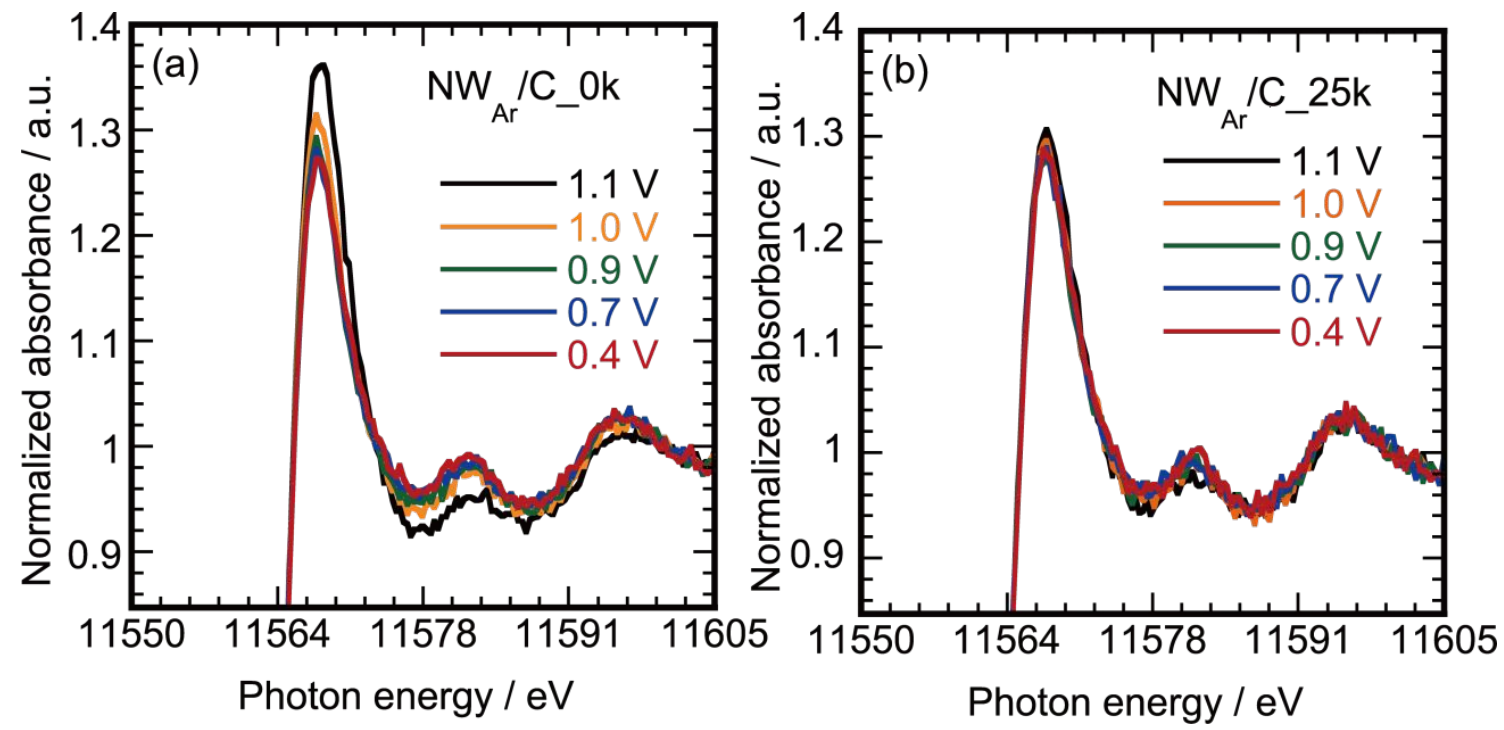

Figure S8. Enlarged potential dependent XANES spectra of (a) $\mathrm{NW}_{\mathrm{Ar}} / \mathrm{C}$ _ok and (b) $\mathrm{NW}_{\mathrm{Ar}} / \mathrm{C} \_25 \mathrm{k}$ in the Pt $L_{3}$ edge white line region. 


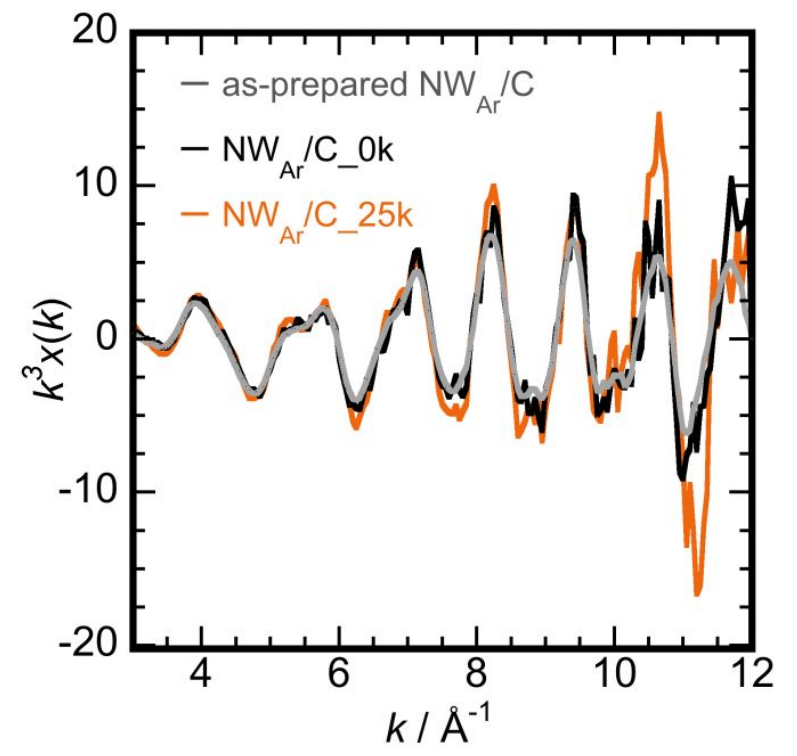

Figure S9. (a) EXAFS oscillation of (a) the as-prepared $\mathrm{NW}_{\mathrm{Ar}} / \mathrm{C}$ collected in the transmission method (the trace in gray) and (b) $\mathrm{NW}_{\mathrm{Ar}} / \mathrm{C}_{-} 0 \mathrm{k}$ (the trace in black) and (c) $\mathrm{NW}_{\mathrm{Ar}} / \mathrm{C} \_25 \mathrm{k}$ (the trace in orange) collected in the fluorescence method. 

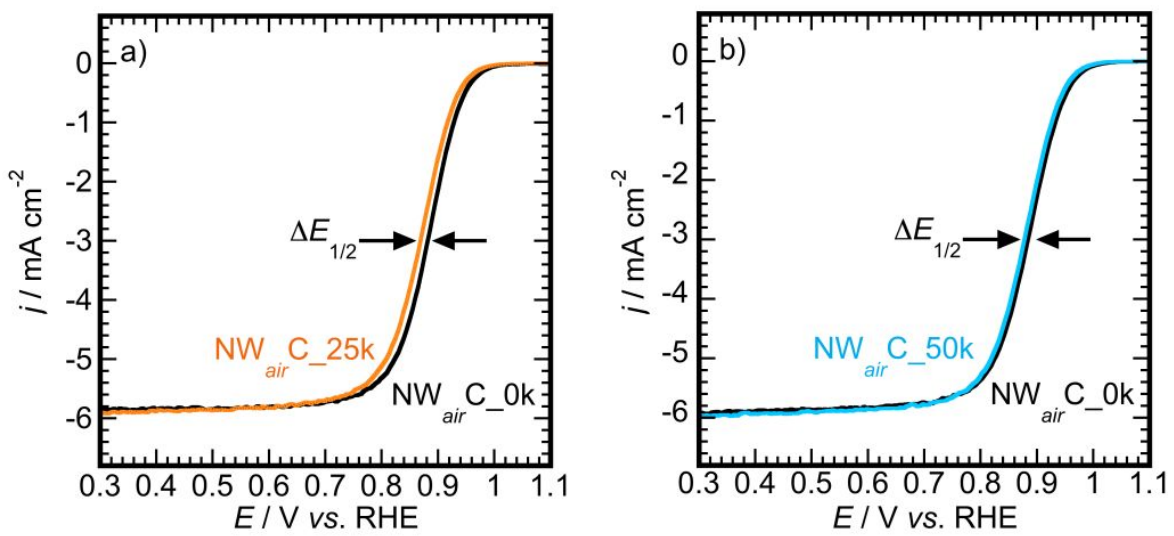

Figure S10. Comparisons of LSVs of $\mathrm{Pt}-\mathrm{Ni} \mathrm{NW}_{\text {air }} / \mathrm{C} \_0 \mathrm{k}$ with (a) $\mathrm{NW}_{\text {air }} / \mathrm{C} \_25 \mathrm{k}$ and (b) $\mathrm{NW}_{\text {air }} / \mathrm{C} \_50 \mathrm{k}$ recorded at $1600 \mathrm{rpm}$ at $10 \mathrm{mV} \mathrm{s}^{-1}$ in a positive-going sweep in a $0.1 \mathrm{M}$ $\mathrm{HClO}_{4}$ aqueous solution under oxygen. 


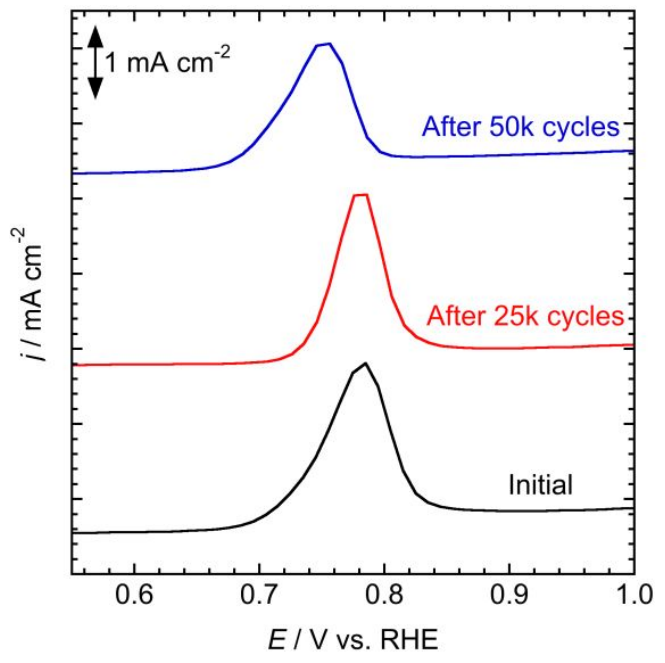

Figure S11. $\mathrm{CO}$ stripping voltammograms of $\mathrm{NW}_{\text {air }} / \mathrm{C}_{-} 0 \mathrm{k}$ (the trace in black), $\mathrm{NW}_{\text {air }} / \mathrm{C} \_25 \mathrm{k}$ (the trace in red) and $\mathrm{NW}_{\text {air }} / \mathrm{C} \_50 \mathrm{k}$ (the trace in blue) recorded at $50 \mathrm{mV}$ $\mathrm{s}^{-1}$ in a $0.1 \mathrm{M} \mathrm{HClO}_{4}$ aqueous solution under Ar. The differences between voltammograms recorded at the first and second cycles are shown for each sample. 
Table S1. Parameters used for curve-fitting analysis of EXAFS oscillations.

\begin{tabular}{|c|c|c|c|c|c|c|}
\hline Sample & $\begin{array}{c}\text { Data } \\
\text { collection } \\
\text { method }\end{array}$ & $\begin{array}{c}\text { Coordination } \\
\text { number }\end{array}$ & $\begin{array}{c}\mathrm{Pt}-\mathrm{Pt} \\
\text { distance / } \\
\AA\end{array}$ & $\Delta \mathrm{E} / \mathrm{eV}$ & $\begin{array}{c}\text { Debye } \\
\text { Waller } \\
\text { factor / } \AA\end{array}$ & $\begin{array}{c}\mathrm{R} \\
/ \%\end{array}$ \\
\hline $\begin{array}{l}\text { As-prepared } \\
\qquad \mathrm{Pt}-\mathrm{Ni} \\
\mathrm{NW}_{\mathrm{Ar}} / \mathrm{C}\end{array}$ & Transmission & $8.8 \pm 1.2$ & $2.74 \pm 0.01$ & $9.3 \pm 1.6$ & $0.080 \pm 0.008$ & 4.8 \\
\hline $\begin{array}{c}\text { As-prepared } \\
\mathrm{Pt-Ni} \\
\mathrm{NW}_{\mathrm{Ar}} / \mathrm{C}\end{array}$ & Fluorescence & $7.0 \pm 1.3$ & $2.74 \pm 0.01$ & $9.6 \pm 2.3$ & $0.055 \pm 0.021$ & 6.4 \\
\hline $\begin{array}{c}\mathrm{Pt}-\mathrm{Ni} \\
\mathrm{NW}_{\mathrm{Ar}} / \mathrm{C} \_25 \mathrm{k}\end{array}$ & Fluorescence & $7.4 \pm 1.6$ & $2.73 \pm 0.01$ & $6.6 \pm 2.6$ & $0.044 \pm 0.028$ & 3.8 \\
\hline
\end{tabular}




\section{References}

1. Sun, Y.; Luo, M.; Qin, Y.; Zhu, S.; Li, Y.; Xu, N.; Meng, X.; Ren, Q.; Wang, L.; Guo,

S. Atomic-Thick PtNi Nanowires Assembled on Graphene for High-Sensitivity Extracellular Hydrogen Peroxide Sensors. ACS Appl. Mater. Interf. 2017, 9, 34715-34721. DOI: $10.1021 /$ acsami.7b11758.

2. Jiang, K.; Zhao, D.; Guo, S.; Zhang, X.; Zhu, X.; Guo, J.; Lu, G.; Huang, X. Efficient oxygen reduction catalysis by subnanometer Pt alloy nanowires. Sci. Adv. 2017, 3, e1601705. DOI: 10.1126/sciadv.1601705.

3. Nagasawa, K.; Takao, S.; Nagamatsu, S.-i.; Samjeské, G.; Sekizawa, O.; Kaneko, T.; Higashi, K.; Yamamoto, T.; Uruga, T.; Iwasawa, Y. Surface-Regulated Nano$\mathrm{SnO} 2 / \mathrm{Pt} 3 \mathrm{Co} / \mathrm{C}$ Cathode Catalysts for Polymer Electrolyte Fuel Cells Fabricated by a Selective Electrochemical Sn Deposition Method. J. Am. Chem. Soc. 2015, 137, 1285612864. DOI: $10.1021 /$ jacs.5b04256.

4. Ravel, B.; Newville, M. ATHENA, ARTEMIS, HEPHAESTUS: data analysis for Xray absorption spectroscopy using IFEFFIT. J Synchrotron Radiat 2005, 12, 537-541. DOI: $10.1107 / \mathrm{S} 0909049505012719$.

5. Taguchi, T. REX2000 Version 2.5: Improved DATA Handling and Enhanced User-Interface. AIP Conf. Proc. 2007, 882, 162-164. DOI: 10.1063/1.2644462.

6. Taguchi, T.; Ozawa, T.; Yashiro, H. REX2000 Yet Another XAFS Analysis Package. Physica Scripta 2005, 205. DOI: 10.1238/physica.topical.115a00205.

7. Asakura, K. In X-Ray Absorption Fine Structure for Catalysts and Surfaces, pp 33-58. 